\title{
SARS-CoV-2 infection in children with chronic kidney disease
}

\author{
Sudarsan Krishnasamy ${ }^{1} \cdot$ Mukta Mantan $^{2} \cdot{\text { Kirtisudha } \text { Mishra }^{3} \cdot K^{2} \text { Kaika Kapoor }}^{4} \cdot$ Megha Brijwal $^{5} \cdot$ Manish Kumar $^{3}$. \\ Shobha Sharma ${ }^{4}$. Swarnim Swarnim ${ }^{2} \cdot$ Rajni Gaind $^{6} \cdot$ Priyanka Khandelwal $^{1} \cdot$ Pankaj Hari $^{1} \cdot$ Aditi Sinha $^{1}$ (D) \\ Arvind Bagga ${ }^{1}$ (1)
}

Received: 6 February 2021 / Revised: 4 July 2021 / Accepted: 5 July 2021 / Published online: 14 September 2021

(c) IPNA 2021

\begin{abstract}
Background Information on the course of SARS-CoV-2 infection in children with chronic kidney disease (CKD) is limited. Methods We retrospectively reviewed the presentation and outcomes of SARS-CoV-2 infection in patients with CKD followed at any of the four pediatric nephrology centers in New Delhi from April 2020 to June 2021. Outcomes, including cardiopulmonary and renal complications, were reported in relation to underlying disease category and illness severity at presentation.

Results Underlying illness in 88 patients included nephrotic syndrome (50\%), other CKD stages 1-4 (18.2\%), CKD 5D (17\%), and CKD 5T (14.8\%). Thirty-two of 61 patients with symptomatic COVID-19 and 9/27 asymptomatic patients were admitted for median 10 (interquartile range 7-15) days. Seventeen (19.3\%) patients developed moderate or severe COVID19. Systemic complications, observed in 30 (34.1\%), included acute kidney injury (AKI, 34.2\%), COVID-19 pneumonia (15.9\%), unrelated pulmonary disease $(2.3 \%)$, and shock $(4.5 \%)$. Nineteen $(21.6 \%)$ had severe complications (AKI stage 2-3, encephalopathy, respiratory failure, shock). Eight (11\%) of twelve (16.4\%) patients with severe AKI required dialysis. Three $(3.4 \%)$ patients, two with steroid-resistant nephrotic syndrome in relapse and one with CKD 1-4, died due to respiratory failure. Univariate logistic regression indicated that patients presenting with nephrotic syndrome in relapse or moderate to severe COVID-19 were at risk of AKI (respective odds ratio, 95\%CI: 3.62, 1.01-12.99; 4.58, 1.06-19.86) and/or severe complications (respective odds ratio, 95\%CI: 5.92, 1.99-17.66; 61.2, 6.99-536.01).

Conclusions Children with CKD presenting with moderate-to-severe COVID-19 or in nephrotic syndrome relapse are at risk of severe complications, including severe AKI and mortality.
\end{abstract}

Keywords Children · Acute kidney injury $\cdot$ COVID-19 $\cdot$ Kidney replacement therapy $\cdot$ Nephrotic syndrome

Aditi Sinha

aditisinhaaiims@gmail.com

1 Division of Nephrology, Department of Pediatrics, All India Institute of Medical Sciences, New Delhi 110029, India

2 Department of Pediatrics, Maulana Azad Medical College and Lok Nayak Jai Prakash Hospital, New Delhi, India

3 Department of Pediatrics, Chacha Nehru Bal Chikitsalaya, Delhi, India

4 Department of Pediatrics, Vardhman Mahavir Medical College and Safdarjung Hospitals, New Delhi, India

5 Department of Microbiology, All India Institute of Medical Sciences, New Delhi, India

6 Department of Microbiology, Vardhman Mahavir Medical College and Safdarjung Hospitals, New Delhi, India

\section{Introduction}

The pandemic of coronavirus disease (COVID-19), caused by severe acute respiratory syndrome coronavirus 2 (SARSCoV-2), is considered to be less widespread and serious in children $[1,2]$. With the exception of multisystem inflammatory syndrome with shock, the disease in childhood is typically milder with lower case fatality than in adult patients [3]. Systematic reviews indicate that patients with chronic kidney disease (CKD) are affected more often, and are at high risk of respiratory morbidity as well as mortality [4]. Information on COVID-19 in children with underlying CKD is presently limited to seven reports on 152 patients, chiefly from Europe and the US [5-11]. Information on children with CKD outside these regions is limited to 38 patients, in a survey by the International Pediatric Nephrology 
Association during March-July 2020 [8]. However, South Asia was likely under-represented because the pandemic affected the region several weeks later than China, Europe and North America. Two distinct waves of the pandemic were observed in India during 2020-21, with cases peaking in September 2020 and May 2021 (Supplementary Fig. 1). Preliminary reports of COVID-19 in Indian children show that the features are similar to those reported elsewhere [12]. We describe here the clinical features and outcomes of consecutive children with CKD who were diagnosed with SARS-CoV-2 infection at four academic centers in New Delhi from April 2020 to June 2021.

\section{Methods}

We reviewed the case records of consecutive patients $\leq 18$ years old with pre-existing CKD and laboratory confirmed SARS-CoV-2 infection, detected at any of four pediatric nephrology centers in New Delhi during the pandemic. Indications for testing patients for SARSCoV-2 infection included: (i) clinical features suggestive of COVID-19 (fever, cough, dyspnea, rhinorrhea, sore throat, diarrhea, myalgia, anosmia or ageusia); (ii) close contact (within 6-ft of an infected person for 15 min or longer) with an individual diagnosed with SARS-CoV-2 infection [13]; or (iii) admission for management of underlying disease. Patients with SARS-CoV-2 infection who developed AKI during hospital stay, but lacked evidence of pre-existing kidney disease, were excluded. Institutional review boards at participating centers approved the study and waived the need for parental or patient consent.

Testing for SARS-CoV-2 infection was performed on nasal and oropharyngeal swabs using reverse transcriptase polymerase chain reaction (RT-PCR) or rapid antigen test (Standard Q COVID-19 Ag kit, SD Biosensor, Gyeonggi-do, Korea), as recommended by the Indian Council of Medical Research (ICMR) [14] and Centers for Disease Control [15]. Given the low sensitivity (85.0\%; 95\% CI 78.3-90.2\%) and high specificity (98.9\%; 95\%CI 98.3-99.4\%) of the antigen test, patients with negative, but not positive, test results underwent retesting by RT-PCR. Retesting for SARS-CoV-2 by RT-PCR, after at least 3 days of confirmed infection, was restricted to patients in whom there was a proposed change in immunosuppressive therapy, or transfer to another hospital for hemodialysis, or were being considered for discharge but isolation at home was not possible. COVID-19 case definition and its categorization into mild, moderate, or severe disease followed the national guidelines (Supplementary Table 1) [16]. Indications for hospital admission were (i) symptomatic infection, particularly in an immunosuppressed host, (ii) management of the underlying illness, and (iii) inability to ensure home isolation. These patients were managed in separate COVID-19 facilities as per current standard of care [16]. Shock, sepsis, acute respiratory distress syndrome (ARDS), and acute kidney injury (AKI) were diagnosed and managed using standard guidelines [16-18]. The prevalence of AKI, severe AKI (KDIGO stages 2 and 3), and kidney replacement therapy (KRT) $[18,19]$ is reported for patients not already on maintenance dialysis. Hemodialysis was provided at two centers dedicated to patients with SARS-CoV-2 infection, following standard recommendations [20, 21]. The effluent of peritoneal dialysis was discarded as per International Society of Peritoneal Dialysis recommendations [22].

Following detection of SARS-CoV-2 infection and for 2 weeks afterwards, immunosuppressive therapy was modified, with minor variations, as follows: (i) if on corticosteroids currently or within the last year, prednisolone was administered at a dose of $0.5 \mathrm{mg} / \mathrm{kg}$ daily for 1 week, (ii) dose of mycophenolate mofetil was reduced by $25-33 \%$; (iii) cyclophosphamide administration was stopped; and (iv) therapy with calcineurin inhibitors (CNI, cyclosporine or tacrolimus) was continued [23]. Therapy with angiotensin converting enzyme inhibitor or angiotensin receptor blocker was continued, except in the presence of AKI. Policies on therapy for COVID-19 varied over time, with non-uniform use of hydroxychloroquine, azithromycin, ivermectin, remdesivir, tocilizumab, and convalescent plasma.

Data on clinical and laboratory findings were reviewed from medical records for details of pre-planned parameters viz. underlying disease, severity of COVID-19 and associated complications, testing methods for SARS-CoV-2 virus and duration of RT-PCR positivity, therapy received and duration of hospital stay. Underlying CKD was categorised as nephrotic syndrome, other kidney diseases with CKD stage 1-4, CKD 5D, and CKD 5T. In patients with nephrotic syndrome, the presence of nephrotic-range proteinuria at evaluation at onset, relapse or following non-response to immunosuppression, was considered as 'relapse'.

Patients were followed up until discharge, death or 4weeks after diagnosis of COVID-19, whichever was earlier. Hypertension was defined using standard guidelines [24]. Estimated glomerular filtration rate (eGFR) was calculated using the modified Schwartz formula [25]. Data is summarized as median (interquartile range, IQR) and proportions (95\% confidence interval, CI) using Stata software, version 14.2 (Stata Corp., College Station, TX). Univariate logistic regression was performed post hoc to examine the association between baseline features and occurrence of AKI or severe complications (AKI stages $2-3$, shock, respiratory distress requiring invasive or non-invasive ventilation, encephalopathy, or death). 


\section{Results}

We report 88 patients (67 boys) with CKD and median age 10 (IQR 6-15) years, who presented between 21 April 2020 and 11 June 2021 (Table 1, Supplementary Fig. 1). Over half the cases were managed at one center; eight patients required inter-hospital transfer for hemodialysis at facilities dedicated for patients with COVID-19. SARSCoV-2 infection was identified by RT-PCR in 83 patients and rapid antigen test in 5 patients. Twenty-seven asymptomatic patients were detected on screening performed at hospital admission for reasons apparently unrelated to
COVID-19 $(n=9)$, low-risk contact with infected individual at hemodialysis facility $(n=7)$, or high-risk contact with family member $(n=11)$. Symptoms, in 61 patients, included fever $(59.1 \%)$, cough $(38.6 \%)$, respiratory distress $(15.9 \%)$ and diarrhea (10.2\%). At onset, the illness was categorized as mild, moderate and severe in 51, eight and two patients, respectively (Table 1 ). Nephrotic syndrome was the most common underlying diagnosis $(n=44)$, with $24(54.5 \%)$ of them in relapse, and $27(61.4 \%)$ having steroid-sensitive illness. Twenty-eight patients were on KRT, including 14 patients on maintenance hemodialysis, one on automated peritoneal dialysis and 13 recipients of kidney transplantation. Supplementary Table 1 and
Table 1 Baseline characteristics of patients with kidney disease and SARS-CoV-2 infection $(n=88)$

\begin{tabular}{|c|c|}
\hline Parameter & $\mathrm{N}(\%)$ \\
\hline Boys & $67(76.1)$ \\
\hline Age, years & $10(6-15)$ \\
\hline \multicolumn{2}{|l|}{ Presentation } \\
\hline Asymptomatic & $27(30.7)$ \\
\hline Symptomatic & $61(69.3)$ \\
\hline Fever & $52(59.1)$ \\
\hline Cough & $34(38.6)$ \\
\hline Respiratory distress & $14(15.9)$ \\
\hline Diarrhea & $9(10.2)$ \\
\hline \multicolumn{2}{|l|}{ Clinical severity of COVID-19 [16] } \\
\hline Asymptomatic & $27(30.7)$ \\
\hline Mild & $51(57.9)$ \\
\hline Moderate & $8(9.1)$ \\
\hline Severe & $2(2.3)$ \\
\hline \multicolumn{2}{|l|}{ Underlying disease } \\
\hline Patients not on kidney replacement therapy & $60(68.2)$ \\
\hline Nephrotic syndrome (relapse/remission) & $44(24 / 20)$ \\
\hline Steroid sensitive (relapse/remission) & $27(14 / 13)$ \\
\hline Steroid resistant (relapse/remission) & $17(10 / 7)$ \\
\hline CAKUT (Reflux nephropathy/pelviureteric junction obstruction/PUV) & $5(2 / 2 / 1)$ \\
\hline Others (HUS, cystic kidneys, Lowe syndrome, Takayasu aortoarteritis, lupus) & $11(3 / 3 / 2 / 2 / 1)$ \\
\hline Patients on kidney replacement therapy & $28(31.8)$ \\
\hline Chronic kidney disease 5D (CAKUT/HUS/FSGS/IgA nephropathy/unknown) & $15(5 / 3 / 2 / 2 / 3)$ \\
\hline $\begin{array}{l}\text { Chronic kidney disease } 5 T \text { (CAKUT/neurogenic bladder/chronic GN/familial } \\
\text { hypomagnesemia hypercalciuria and nephrocalcinosis / unknown) }\end{array}$ & $13(5 / 2 / 2 / 1 / 3)$ \\
\hline Current immunosuppression & $50(56.8)$ \\
\hline Prednisolone & 40 \\
\hline Mycophenolate mofetil & 17 \\
\hline Calcineurin inhibitors ( $<3$ months back) & 25 \\
\hline Cyclophosphamide ( $<4$ weeks back) & 3 \\
\hline IV rituximab ( $<6$ months back) & 2 \\
\hline Estimated glomerular filtration rate (eGFR), $\mathrm{ml} /$ minute per $1.73 \mathrm{~m}^{2 *}$ & $81.9[39.8-104.1]$ \\
\hline
\end{tabular}

Data is shown as n (\%) or median [interquartile range]; CAKUT congenital anomalies of the kidney and urinary tract; FSGS, focal segmental glomerulosclerosis; GN, glomerulonephritis; HUS, hemolytic uremic syndrome; $I V$, intravenous; $P U V$, posterior urethral valves

*Excluding 15 patients already on dialysis; eGFR at presentation calculated using modified Schwartz formula based on serum creatinine at diagnosis of SARS-CoV-2 infection 
Supplementary Figs. 2 and 3 provide details of underlying disease in relation to COVID-19 severity at presentation.

Fifty $(56.8 \%)$ patients were either receiving, or had recently discontinued immunosuppressive drugs (Table 1). Medications included prednisolone $(n=40), \mathrm{CNI}(n=25)$, or mycophenolate mofetil $(n=17)$; three patients had discontinued therapy with $\mathrm{CNI}<2$ months back (Supplementary Table 2). Patients included 32 with nephrotic syndrome and 13 allograft recipients, transplanted more than 1 year previously and on stable immunosuppression (Supplementary Table 2). Two of three patients with anti-factor $\mathrm{H}$ associated hemolytic uremic syndrome on hemodialysis were receiving oral prednisolone and IV cyclophosphamide, while the third was on maintenance oral prednisolone and mycophenolate mofetil. One patient with steroid-resistant nephrotic syndrome on maintenance hemodialysis had received rituximab 4 months prior for desensitization in preparation for living related kidney transplantation. One patient with severe flare of lupus, while on therapy with mycophenolate mofetil and prednisolone, had received high dose methylprednisolone, intravenous immunoglobulin (IVIG) and one dose of rituxi$\mathrm{mab}\left(750 \mathrm{mg} / \mathrm{m}^{2}\right) 2$ weeks prior to admission. Seven patients treated with IV rituximab 2-4 years prior were not deemed immunosuppressed.

\section{Course and complications}

Twenty-nine patients with COVID-19 symptoms and 18 asymptomatic patients were managed at home (Supplementary Figs. 2 and 3). Thirty-two patients were admitted for monitoring of symptomatic COVID-19 and nine were admitted for complications of the underlying illness, including five patients with nephrotic syndrome and anasarca, and two patients each with severe anemia and asymptomatic allograft dysfunction. Admission to the intensive care unit was indicated in 18 patients for moderate to severe COVID-19 $(n=8)$, monitoring for AKI $(n=6)$ or anasarca $(n=3)$, and respiratory distress due to pulmonary tuberculosis $(n=1)$. Five of the eight patients who presented with moderate to severe COVID-19 and admitted to the intensive care unit had underlying CKD 1-4, while two were kidney allograft recipients and one patient had relapse of steroid-dependent nephrotic syndrome. Seven patients with nephrotic syndrome in relapse were admitted with asymptomatic or mild COVID-19 and evolved to moderate or severe COVID-19 during hospital stay (Supplementary Figs. 3-4; Supplementary Tables 1 and 3).

Pulmonary, hemodynamic, and/or renal complications were observed in $30(34.1 \%)$ patients. Pulmonary disease, observed in $16(18.2 \%)$ cases, included 14 patients with COVID pneumonia; 7 of whom were in relapse of nephrotic syndrome with five requiring mechanical ventilation and two non-invasive ventilation, 3 were CKD 1-4 with one each receiving invasive and non-invasive ventilation and face mask oxygen, 2 were CKD 5T on non-invasive ventilation and 2 patients with CKD 5D managed on supplemental oxygen (Table 2, Supplementary Table 3 and Supplementary Fig. 4b). One patient with steroid-dependent nephrotic syndrome with severe AKI and fluid overload was mechanically ventilated for pulmonary edema while another with CKD 5D

Table 2 Outcomes of children with kidney diseases affected by COVID-19 $(n=88)$

\begin{tabular}{ll}
\hline Parameter & $\mathrm{N}(\%)$ \\
\hline Hospital admission $^{\#}$ & $41(46.6)$ \\
Admission to intensive care unit & $18(20.4)$ \\
Maximal clinical severity of COVID-19 & \\
Asymptomatic & $25(28.4)$ \\
Mild & $46(52.3)$ \\
Moderate & $9(10.2)$ \\
Severe & $8(9.1)$ \\
Maximal respiratory support required & \\
Oxygen by face mask & 5 \\
High flow nasal cannula & 5 \\
Mechanical ventilation & 6 \\
Vasopressor support & $4(4.5)$ \\
Acute kidney injury & \\
Stage 1 & $25(34.2)$ \\
Stage 2 & 13 \\
Stage 3 & 2 \\
Need for kidney replacement therapy & 10 \\
Outcome & 8 \\
Discharge; well at home (not admitted) & \\
Death & $38 ; 48$ \\
Re-admission & $3(3.4)$ \\
Duration of hospital stay, days & 2 \\
Outcomes in patients with AKI n=25) & $10(7-15)$ \\
Continued need for kidney replacement therapy & 2 \\
Estimated GFR*, ml/min/1.73 m ${ }^{2}$ & $65.6[40-84.3]$ \\
Hypertension; proteinuria (new onset) & \\
Retesting for clearance of infection & $2 ; 2$ \\
Time to negative test result, days & 33 \\
Persistent positive for $>14$ days & $15(8-24)$ \\
Persistent positive for $>21$ days & $18(54.5)$ \\
Persistent positive for $>6$ weeks & \\
\hline & \\
\hline
\end{tabular}

Data reported as n (\%) or median [interquartile range]

\#Included 9 admissions for problems apparently unrelated to COVID19 (anasarca in 5 patients with nephrotic syndrome; asymptomatic allograft dysfunction and severe anemia in two patients each); assessed only in patients not already on dialysis; ${ }^{\$} 4$ patients were not admitted and recovered with oral hydration at home; *eGFR calculated using modified Schwartz formula [25] based on serum creatinine at discharge in patients not on dialysis; ${ }^{\circledR}$ hypertension defined as per clinical practice guidelines of the American Academy of Pediatrics 2017 [24] 
and pulmonary tuberculosis received supplemental oxygen. Although they were SARS-CoV-2 positive, the respiratory worsening appeared unrelated to COVID-19.

Shock was noted in four patients, including three with nephrotic syndrome in relapse and one with CKD 4. A 6-year-old patient with steroid-dependent nephrotic syndrome presented with seizures and encephalopathy and developed shock within $6 \mathrm{~h}$ of admission; shock recovered and sensorium improved following aggressive inotropic support, mechanical ventilation and antibiotics. Two patients with steroid-resistant nephrotic syndrome and with persistent viral shedding developed refractory shock on days 7 and 66 of hospital stay and died within hours; shock was considered secondary to fulminant bacterial sepsis in the latter patient. A 15-year-old girl with CKD 4 secondary to reflux nephropathy was mechanically ventilated at presentation with severe ARDS and shock; the child died 6 days later due to ARDS and refractory shock.

AKI was present in 25 children, 21 of whom were admitted. Sixteen children had AKI at admission, including seven patients with nephrotic syndrome in relapse, four patients with CKD 1-4 and five transplant recipients. Four patients, including two each with steroid-sensitive nephrotic syndrome in relapse and CKD 1-4, developed AKI after a median 3 (IQR 2.75-3.5) days of hospital stay; one patient with steroid-resistant nephrotic syndrome developed AKI 6 weeks after admission secondary to bacterial sepsis and multiorgan dysfunction. Two transplant recipients and two patients with steroid-resistant nephrotic syndrome who were isolated at home developed stage $1 \mathrm{AKI}$, which resolved spontaneously. Supplementary Fig. 4c and Supplementary Table 4 indicate the evolution of AKI based on disease category and disease severity at presentation. Twelve patients had severe AKI (stages 2-3), including seven patients with relapse of nephrotic syndrome, and five with CKD 1-4 (Table 2, Supplementary Table 4). Eight of these 12 patients required KRT (seven hemodialysis, one peritoneal dialysis). For patients not already on dialysis, the prevalence $(95 \%$ CI) of AKI, severe AKI and KRT were estimated at 34.2\% (24.4-45.7\%), 16.4\% (9.7-26.6\%), and 11\% (5.7-20.2\%), respectively. Similarly, the prevalence $(95 \% \mathrm{CI})$ of AKI, severe AKI and KRT for patients admitted to the intensive care unit were $83.3 \%$ (60.8-94.2\%), 55.6\% (33.7-75.4\%), and $38.9 \%(20.3-61.4 \%)$, respectively.

\section{Immunosuppression and specific management}

Immunosuppression was modified for 30 patients, including stress dosing of corticosteroids ( $n=23)$, reduction or discontinuation of mycophenolate mofetil $(n=6)$, stopping therapy with calcineurin inhibitors $(n=4)$, and cyclophosphamide $(n=3)$. Thirty-six patients received empiric therapy for SARS-CoV-2 infection, including azithromycin $(n=28)$, ivermectin $(n=7)$, remdesivir $(n=5)$, hydroxychloroquine $(n=3)$, and convalescent plasma and IV tocilizumab (one each).

\section{Outcomes}

Three out of 88 patients, two with steroid-resistant nephrotic syndrome in relapse and one with CKD 1-4, died, leading to an estimated mortality of 3.4\% (95\% CI 1.2-9.6\%) (Supplementary Fig. 4d). Death was attributed to ARDS due to COVID-19 in two children; the third patient, in addition to being SARS-CoV-2 positive until death, had superadded bacterial sepsis. The remaining 38 patients were discharged after median stay of $10(7-15)$ days without any cardiopulmonary sequelae (Supplementary Figs. 2-4 and Supplementary Tables 3-4). Of the 47 patients isolated at home, four developed AKI stage 1, which resolved spontaneously; others recovered without complications.

The median time to SARS-CoV-2 RT-PCR negative test result, in 33 patients, was 15 (8-24) days. Eleven patients, four with relapse of steroid-resistant nephrotic syndrome, three each with CKD 5D and CKD 5T, and one with Lowe syndrome showed viral shedding beyond 3 weeks; eight of these were immunosuppressed. Persistent viral shedding beyond 6 weeks was seen in one patient each with steroidresistant nephrotic syndrome, CKD 5T and CKD 5D; the latter was not on immunosuppression. Two patients with steroid-resistant nephrotic syndrome were readmitted for anasarca and severe AKI with positive RT-PCR; while one had tested negative by RT-PCR at prior discharge on day 14, the test was persistently positive in the other patient until his death on day 66.

For admitted patients not already on dialysis, the eGFR increased from $81.9(39.8-104.1) \mathrm{ml} / \mathrm{min} / 1.73 \mathrm{~m}^{2}$ at presentation to $90.2(56.3-109.4) \mathrm{ml} / \mathrm{min} / 1.73 \mathrm{~m}^{2}$ at last follow-up $(P=0.008)$ (Table 1). Similarly, the eGFR in patients with AKI increased from $33.3(25.5-56.5)$ to $65.6(40-84.3) \mathrm{ml} /$ $\mathrm{min} / 1.73 \mathrm{~m}^{2}$ at last follow-up $(P=0.0001)$ (Table 2). Six of 8 patients who required KRT during admission could discontinue dialysis; two patients died while on dialysis.

\section{Determinants of outcomes}

The duration of hospital stay $(n=41)$ and viral shedding $(n=33)$ were unrelated to sex, age, COVID-19 symptoms, underlying disease, immunosuppression or presence of complications. Univariate logistic regression suggested that presentation with moderate to severe COVID-19 or in relapse of 
nephrotic syndrome were associated with occurrence of AKI and severe complications (Table 3 ).

\section{Discussion}

We describe the presentation and outcomes of SARS-CoV-2 infection in 88 pediatric patients with CKD managed at four academic centers in New Delhi over a period of 14 months. The incidence of cases corresponded to the peaks of the two waves of the pandemic in 2020 and 2021 (Supplementary Fig. 1). The chief underlying illness was nephrotic syndrome in half the patients and included children in remission as well as relapse. Half the patients were immunosuppressed and one third were either receiving chronic dialysis or had received a kidney allograft in the past. Two thirds of patients were symptomatic, chiefly with fever or respiratory symptoms, and one-fifth required respiratory support. Although one-third of patients not already on maintenance dialysis developed AKI, only one-third of those who developed AKI required KRT. While the majority of patients with CKD recovered from SARS-CoV-2 infection, three patients died, secondary to multiorgan failure and systemic sepsis. Our findings suggest that patients with CKD who present with moderate to severe COVID-19 or with relapse of nephrotic syndrome were at risk of severe complications, including AKI and mortality.

Systematic reviews describe more severe COVID-19 disease and higher rates of adverse outcomes, including AKI and mortality, in adult patients with CKD [4, 24-27]. In contrast, studies in children with CKD, summarized in Table 4, indicate a relatively milder course of illness [5-11]. These children, predominantly boys (49-74\%) had median age of
9-12 years, and the most common underlying diagnosis was nephrotic syndrome. Kidney allograft recipients and patients on dialysis constituted $11-100 \%$ and $14-47 \%$ cases, respectively. The rates of symptomatic COVID-19 (8-81\%) and hospitalization (31-60\%) were similar to those in population-based studies [28-30]; severe respiratory illness (9-12\%) and mortality (3.5-4\%) were also infrequent. Since previous reports chiefly included children from Europe, UK, and North America, this report from India underscores the similarities in severity of SARS-CoV-2 infection and disease presentation in patients with CKD across geographic regions.

Available reports emphasize the relatively low incidence of SARS-CoV-2 infection in immunosuppressed patients [8, $10,31,32]$. Our experience was similar, although patient contact has been limited and chiefly through teleconsultations. Regular teleconsultations at one center, over 14 months, resulted in documentation of SARS-CoV-2 infection in thirteen of 80 allograft recipients, ten of $\sim 350$ patients with nephrotic syndrome administered rituximab previously, and seventeen of almost 800 patients with nephrotic syndrome enrolled in longitudinal cohorts or in randomized studies. However, the limitations imposed by such consultations and lack of opportunities for viral testing might have underestimated the prevalence of SARS-CoV-2 infection in these patients. In the absence of high mortality or morbidity, continuing immunosuppression in standard doses appears rational. In view of concerns of intense immunosuppression, we have refrained from using IV rituximab since the beginning of the pandemic [33]. Similar to the course in a patient with granulomatosis with polyangiitis [34], one patient with lupus nephritis in the present report developed severe COVID-19 following therapy with rituximab, but improved
Table 3 Risk factors for AKI and severe complications (severe acute kidney injury, invasive/non-invasive ventilation, encephalopathy, shock or death)

\begin{tabular}{llll}
\hline Baseline variable & \multicolumn{3}{l}{ Univariate logistic regression } \\
\hline Outcome: AKI $(\mathbf{n} / \mathbf{N}=\mathbf{2 5 / 7 3})^{*}$ & Odds ratio & $\mathbf{9 5 \%} \mathbf{C I}$ & $\boldsymbol{P}$ \\
Age, years & 0.91 & $0.81,1.04$ & 0.16 \\
Sex, boys & 0.56 & $0.11,2.85$ & 0.49 \\
Nephrotic syndrome in relapse & 3.62 & $1.01,12.99$ & 0.048 \\
Estimated glomerular filtration rate, $\mathrm{ml} / \mathrm{min}$ per $1.73 \mathrm{~m}^{2 \wedge}$ & 1.00 & $0.99,1.02$ & 0.66 \\
Recent or current immunosuppression & 0.49 & $0.14,1.70$ & 0.47 \\
Moderate or severe COVID-19 & 4.58 & $1.06,19.86$ & 0.042 \\
Outcome: Severe complications $(\mathbf{n} / \mathbf{N}=\mathbf{1 9 / 8 8})$ & $\mathbf{O d d s}$ ratio & $\mathbf{9 5 \%} \mathbf{C I}$ & $\boldsymbol{P}$ \\
Age, years & 0.96 & $0.87,1.06$ & 0.43 \\
Sex, boys & 0.82 & $0.24,2.79$ & 0.75 \\
Nephrotic syndrome in relapse & 5.92 & $1.99,17.66$ & 0.001 \\
Estimated glomerular filtration rate, $\mathrm{ml} / \mathrm{min}$ per $1.73 \mathrm{~m}^{2 \wedge}$ & 1.00 & $0.98,1.02$ & 0.81 \\
Recent or current immunosuppression & 1.87 & $0.64,5.50$ & 0.25 \\
Moderate or severe COVID-19 & 61.2 & $6.99,536.01$ & $<0.001$ \\
\hline
\end{tabular}

*Patients with CKD 5D were excluded from analysis

$\wedge$ Pre-illness, in last $<3$ months 
Table 4 Findings in studies on children with kidney diseases and SARS-CoV-2 infection

\begin{tabular}{|c|c|c|c|c|c|c|c|c|}
\hline Author [ref] & Marlais [8] & Marlais [5] & Melgosa [7] & Schwierzeck [11] & Plumb [6] & Mastrangelo [10] & Basalely [9] & Present work \\
\hline $\mathrm{N}$ (countries) & $113(30)$ & $18^{*}(11)$ & 16 (Spain) & 13 (Germany) & 5 (UK) & 3 (Italy) & 2 (USA) & 88 (India) \\
\hline Boys, \% & 49 & 61 & 56.3 & NA & 80 & NA & 100 & 76.1 \\
\hline Median age, years & 11 & 11.5 & 12.3 & $\sim 10$ & 11 & NA & $1, \mathrm{NA}$ & 10 \\
\hline Underlying disease, $\%$ & & & & & NA & & & \\
\hline $\begin{array}{l}\text { Nephrotic syndrome (\% } \\
\text { in relapse) }\end{array}$ & 27 (NA) & 17 (NA) & $31.3(12.5)$ & 0 & & 0 & 50 (NA) & $50(52.3)$ \\
\hline Other glomerular CKD & 23.9 & 17 & 50 & 0 & & 33.3 & 0 & 4.5 \\
\hline Non-glomerular CKD & 2.6 & 0 & 50 & 0 & & 66.7 & 0 & 13.6 \\
\hline CKD 5D & $10.6^{\wedge}$ & 6 & 18.8 & 100 & & 0 & 50 & 17 \\
\hline CKD 5T & 47 & 61 & 18.8 & 0 & & 0 & 0 & 14.8 \\
\hline Immunosuppressed, \% & 100 & 100 & 56.3 & NA & NA & 33.3 & 0 & 56.8 \\
\hline $\begin{array}{l}\text { Symptoms of COVID- } \\
19, \%\end{array}$ & 81.4 & NA & 81.3 & 7.7 & NA & 66.7 & 100 & 68.2 \\
\hline Admitted, $\%$ & 60.2 & 61 & 50 & NA & NA & NA & 100 & 46.6 \\
\hline Respiratory support, $\%$ & 22.1 & 17 & 0 & NA & NA & 0 & 50 & 18.2 \\
\hline Acute kidney injury, $\%$ & NA & NA & 18.8 & NA & NA & 0 & 0 & 34.2 \\
\hline Death, $\%$ & 3.5 & NA & 0 & 0 & NA & 0 & 0 & 3.4 \\
\hline $\begin{array}{l}\text { Predictors of severe } \\
\text { complications }\end{array}$ & None $^{\# 1}$ & NA & NA & NA & NA & NA & NA & Reported $^{\# 2}$ \\
\hline
\end{tabular}

NA not available

*These patients were also included in the study in column 1

^Includes children with glomerular or non-glomerular CKD or CKD5T on dialysis

${ }^{\# 1}$ All 4 deaths were reported in low-n-income countries; ${ }^{\# 2}$ Risk factors included moderate or severe COVID-19; nephrotic syndrome in relapse

rapidly. While biologicals might favorably influence the interplay of infectious and inflammatory mechanisms [35, $36]$, the trends of higher respiratory morbidity and mortality [37-39] emphasize that such therapies be used cautiously.

The experience with COVID-19 in immunosuppressed recipients or solid organ transplants is varied [40-42]. A systematic review including 1,500 kidney transplants among 2,772 solid organ recipients, indicated high rates of admission to intensive care units $(29 \%)$ and higher mortality (18.6\%) [42]. In contrast, outcomes in pediatric transplant recipients appear satisfactory $[8,10]$, with low rates of symptomatic infections [10], mild symptoms, few complications, and similar time to viral clearance as non-immunosuppressed children [7, 8]. Persistent viral excretion in 11 patients in the present report was unrelated to ongoing immunosuppression but was related to COVID-19 severity, as was reported previously [43].

Systematic reviews suggest that AKI affects $11 \%$ of patients admitted with COVID-19 and that $6.8 \%$ of admitted patients require KRT [4]. Furthermore, severe AKI and the need for KRT are reported to be more frequent in patients with CKD [26, 27]. Unsurprisingly, therefore, AKI was the chief extrapulmonary complication of SARS-CoV-2 infection in the present series, and affected $40 \%$ patients who were previously not on KRT. The presence of nephrotic syndrome in relapse appears to be associated with an almost five-fold risk of severe AKI, perhaps due to associated hypovolemia and/or use of diuretics, ACE-inhibitors and other nephrotoxic medications [44]. Similarly, patients with nephrotic syndrome in relapse have higher risk of mechanical ventilation and mortality probably due to edema and respiratory distress. While presentation with moderate to severe COVID-19 and relapse of nephrotic syndrome might be associated with severe complications and death, the wide confidence intervals of these estimates and inability to demonstrate independent association or causality, caution against over-emphasizing these risks. More data is required to explore these findings further.

The present report is one of the larger studies of the impact of COVID-19 on children with CKD, and the first from a developing country. Strengths of the study were the inclusion of consecutive patients diagnosed at four centers in New Delhi, robust diagnosis relying chiefly on RT-PCR, and information on course and complications during a minimum follow-up of 4 weeks. However, the extent of evaluation varied based on whether patients were admitted or isolated at home, and there was heterogeneity in policies on management and documentation of viral clearance. As guidelines for retesting evolved, it was not performed in all patients. Finally, contributions of stress dosing of steroids, ongoing 
hydroxychloroquine intake, relapse of nephrotic syndrome and cytokine responses in certain population groups on disease course are unclear. While these findings replicate the experience from other regions, patients presenting with moderate to severe COVID-19 or with relapse of nephrotic syndrome appear to be at risk of complicated COVID-19, indicating the need for close monitoring.

Supplementary Information The online version contains supplementary material available at https://doi.org/10.1007/s00467-021-05218-1.

Acknowledgements The authors acknowledge the services provided by the Microbiology laboratories at the four participating centers and Department of Health Research (DHR), Indian Council of Medical Research (ICMR) in enabling diagnosis of SARS-CoV-2. The DHR, ICMR is acknowledged for funding and support provided to the Regional Virus Research and Diagnostic Laboratory at the Department of Microbiology, AIIMS, New Delhi. We thank the ICMR for funding to the Advanced Centre for Research in Pediatric Kidney Diseases, Division of Nephrology, Department of Pediatrics, AIIMS, New Delhi [5/7/1090/2013-RHN].

Author contribution SK, MM, KM, KK, MK, SS, SS, AS, and PK collated the data from patients' case records; $\mathrm{MB}$ and RG performed microbiological studies; SK, AS, PH and AB designed the study, analyzed the data and wrote the first draft; all authors refined the manuscript draft and approved the final manuscript.

Data availability Anonymized data will be shared if requested.

\section{Declarations}

Ethics approval The Ethics committees at the four centers waived the need for patient and parental consent.

Consent to participate The Ethics committees at the four centers waived the need for patient and parental consent to participate in the study.

Consent to publication All authors agree with the content of the manuscript, are responsible for the correctness of the statements provided in the manuscript and have consented to submit it for publication. All authors have obtained consent from the responsible authorities at the four Institutes where the work has been carried out, before submission for consideration for publication.

Competing interests The authors declare no competing interests.

\section{References}

1. Epidemiology Working Group for NCIP Epidemic Response, Center C, for Disease Control and Prevention (2020) The epidemiological characteristics of an outbreak of 2019 novel coronavirus diseases (COVID-19) in China. Zhonghua Liu Xing Bing Xue Za Zhi 41:145-151

2. Gupta S, Malhotra N, Gupta N, Agrawal S, Ish P (2020) The curious case of coronavirus disease 2019 (COVID-19) in children. J Pediatr 222:258-259
3. Ludvigsson JF (2020) Systematic review of COVID-19 in children shows milder cases and a better prognosis than adults. Acta Paediatr 109:1088-1095

4. Kunutsor SK, Laukkanen JA (2020) Renal complications in COVID-19: A systematic review and meta-analysis. Ann Med 52:345-353

5. Marlais M, Wlodkowski T, Vivarelli M, Pape L, Tönshoff B, Schaefer F, Tullus K (2020) The severity of COVID-19 in children on immunosuppressive medication. Lancet Child Adolesc Health 4:e17-e18

6. Plumb L, Benoy-Deeney F, Casula A, Braddon FEM, Tse Y, Inward C, Marks S, Steenkamp R, Medcalf J, Nitsch D (2021) COVID-19 in children with chronic kidney disease: Findings from the UK renal registry. Arch Dis Child 106:e16

7. Melgosa M, Madrid A, Alvárez O, Lumbreras J, Nieto F, Parada E, Perez-Beltrán V, Association SPN (2020) SARS-CoV-2 infection in Spanish children with chronic kidney pathologies. Pediatr Nephrol 35:1521-1524

8. Marlais M, Wlodkowski T, Al-Akash S, Ananin P, Bandi VK, Baudouin V, Boyer O, Vásquez L, Govindan S, Hooman N, Ijaz I, Loza R, Melgosa M, Pande N, Pape L, Saha A, Samsonov D, Schreuder MF, Sharma J, Siddiqui S, Sinha R, Stewart H, Tasic V, Tönshoff B, Twombley K, Upadhyay K, Vivarelli M, Weaver DJ, Woroniecki R, Schaefer F, Tullus K (2020) COVID-19 in children treated with immunosuppressive medication for kidney diseases. Arch Dis Child. https://doi.org/10.1136/archdischild-2020-320616

9. Basalely A, Brathwaite K, Duong D, Liu D, Mazo A, Xie Y, Del Rio M, Goilav B, Hayde N, Kaskel FJ, Zolotnitskaya A, Reidy KJ (2021) COVID-19 in children with kidney disease: A report of 2 cases. Kidney Med 3:120-123

10. Mastrangelo A, Morello W, Vidal E, Guzzo I, Annicchiarico Petruzzelli L, Benetti E, Materassi M, Giordano M, Pasini A, Corrado C, Puccio G, Chimenz R, Pecoraro C, Massella L, Peruzzi L, Montini G; COVID-19 task force of the Italian Society of Pediatric Nephrology (2021) Impact of COVID-19 pandemic in children with CKD or immunosuppression. Clin J Am Soc Nephrol 16:449-451

11. Schwierzeck V, König JC, Kühn J, Mellmann A, Correa-Martínez CL, Omran H, Konrad M, Kaiser T, Kampmeier S (2021) First reported nosocomial outbreak of severe acute respiratory syndrome coronavirus 2 (SARS-CoV-2) in a pediatric dialysis unit. Clin Infect Dis 72:265-270

12. Jat KR, Sankar J, Das RR, Ratageri VH, Choudhary B, Bhat JI, Mishra B, Bhatnagar S, Behera B, Charoo BA, Goyal JP, Gupta AK, Gulla KM, Gera R, Illalu S, Kabra SK, Khera D, Kumar B, Lodha R, Mohan A, Mohanty PK, Satapathy AK, Singh K, Singh A, Sharma SV, Tiwari P, Trikha A, Wari PK; Collaborative Indian Pediatric COVID study group (2021) Clinical profile and risk factors for severe disease in 402 children hospitalized with SARS-CoV-2 from India: Collaborative Indian Pediatric COVID Study Group. J Trop Pediatr 67:fmab048

13. World Health Organization (2020) Contact tracing in the context of COVID-19: Interim Guidance. https://www.who.int/publicatio ns/i/item/contact-tracing-in-the-context-of-covid-19. Accessed 25 October 2020

14. Indian Council of Medical Research (2020) advisory on strategy for COVID-19 testing in India. https://www.icmr.gov.in/pdf/covid/ strategy/Testing_Strategy_v6_04092020.pdf. Accessed 10 October 2020

15. Centers for Disease Control (2020) SARS-CoV-2 (COVID-19) Fact Sheet: Guidance - Proposed use of point-of-care (POC) testing platforms for SARS-CoV-2 (COVID-19). https://www.cdc. gov/coronavirus/2019-ncov/downloads/OASH-COVID-19-guida nce-testing-platforms.pdf. Accessed 25 October 2020

16. Directorate General of Health Services (EMR Division), Ministry of Health and Family Welfare, Government of India (version 4) (2020) 
Clinical management protocol: COVID-19. https://www.mohfw.gov. in/pdf/ClinicalManagementProtocolforCOVID19dated27062020. pdf. Accessed 25 Oct 2020

17. Edelson DP, Sasson C, Chan PS, Atkins DL, Aziz K, Becker LB, Berg RA, Bradley SM, Brooks SC, Cheng A, Escobedo M, Flores GE, Girotra S, Hsu A, Kamath-Rayne BD, Lee HC, Lehotsky RE, Mancini ME, Merchant RM, Nadkarni VM, Panchal AR, Peberdy MAR, Raymond TT, Walsh B, Wang DS, Zelop CM, Topjian AA (2020) Interim guidance for basic and advanced life support in adults, children, and neonates with suspected or confirmed COVID19: From the Emergency Cardiovascular Care Committee and Get With The Guidelines-Resuscitation Adult and Pediatric Task Forces of the American Heart Association. Circulation 141:e933-e943

18. Kellum JA, Lameire N, Aspelin P, Barsoum RS, Burdmann EA, Goldstein SL, Herzog CA, Joannidis M, Kribben A, Levey AS (2012) Kidney Disease: Improving Global Outcomes (KDIGO) Acute Kidney Injury Workgroup. KDIGO Clinical Practice Guideline for Acute Kidney Injury. Kidney Int Suppl 2:1-138

19. Basu RK, Kaddourah A, Goldstein SL; AWARE Study Investigators (2018) Assessment of a renal angina index for prediction of severe acute kidney injury in critically ill children: A multicentre, multinational, prospective observational study. Lancet Child Adolesc Health 2:112-120

20. Centers for Disease Control (2020) Interim SARS-CoV-2 testing guidelines for patients in outpatient hemodialysis facilities. https:// www.cdc.gov/coronavirus/2019-ncov/hcp/dialysis/testing-patients. html. Accessed 25 October 2020

21. Ministry of Health \& Family Welfare, Government of India (2020) Guidelines for dialysis of COVID-19 patients. https://www.mohfw. gov.in/pdf/GuidelinesforDialysisofCovid19Patients.pdf. Accessed 25 October 2020

22. International Society for Peritoneal Dialysis (2020) Strategies regarding COVID-19 in PD patients. https://ispd.org/wp-content/ uploads/ISPD-PD-management-in-COVID-19_ENG.pdf. Accessed 25 October 2020

23. Vasudevan A, Mantan M, Krishnamurthy S, Pais P, Mathew G, Hari P, Kanitkar M, Gulati S, Bagga A, Mishra OP; Indian Society of Pediatric Nephrology (2020) Managing children with renal diseases during the COVID-19 pandemic. Indian Pediatr 57:641-651

24. Flynn JT, Kaelber DC, Baker-Smith CM, Blowey D, Carroll AE, Daniels SR, de Ferranti SD, Dionne JM, Falkner B, Flinn SK, Gidding SS, Goodwin C, Leu MG, Powers ME, Rea C, Samuels J, Simasek M, Thaker VV, Urbina EM; Subcommittee on Screening and Management of High Blood Pressure in Children (2017) Clinical Practice Guideline for Screening and Management of High Blood Pressure in Children and Adolescents. Pediatrics 140:e20171904

25. Schwartz GJ, Muñoz A, Schneider MF, Mak RH, Kaskel F, Warady BA, Furth SL (2009) New equations to estimate GFR in children with CKD. J Am Soc Nephrol 20:629-637

26. Coca A, Burballa C, Centellas-Pérez FJ, Pérez-Sáez MJ, Bustamante-Munguira E, Ortega A, Dueñas C, Arenas MD, PérezMartínez J, Ruiz G, Crespo M, Llamas F, Bustamante-Munguira J, Pascual J (2020) Outcomes of COVID-19 among hospitalized patients with non-dialysis CKD. Front Med (Lausanne) 7:615312

27. Kang SH, Kim SW, Kim AY, Cho KH, Park JW, Do JY (2020) Association between chronic kidney disease or acute kidney injury and clinical outcomes in COVID-19 patients. J Korean Med Sci 35:e434

28. Chan L, Chaudhary K, Saha A, Chauhan K, Vaid A, Zhao S, Paranjpe I, Somani S, Richter F, Miotto R, Lala A, Kia A, Timsina P, Li L, Freeman R, Chen R, Narula J, Just AC, Horowitz C, Fayad Z, Cordon-Cardo C, Schadt E, Levin MA, Reich DL, Fuster V, Murphy B, He JC, Charney AW, Böttinger EP, Glicksberg BS, Coca SG, Nadkarni GN; Mount Sinai COVID Informatics Center (MSCIC) (2021) AKI in hospitalized patients with COVID-19. J Am Soc Nephrol 32:151-160
29. Liu YF, Zhang Z, Pan XL, Xing GL, Zhang Y, Liu ZS, Tu SH (2021) The chronic kidney disease and acute kidney injury involvement in COVID-19 pandemic: A systematic review and meta-analysis. PLoS One 16:e244779

30. Götzinger F, Santiago-García B, Noguera-Julián A, Lanaspa M, Lancella L, Calò Carducci FI, Gabrovska N, Velizarova S, Prunk P, Osterman V, Krivec U, Lo Vecchio A, Shingadia D, SorianoArandes A, Melendo S, Lanari M, Pierantoni L, Wagner N, L'Huillier AG, Heininger U, Ritz N, Bandi S, Krajcar N, Roglić S, Santos M, Christiaens C, Creuven M, Buonsenso D, Welch SB, Bogyi M, Brinkmann F, Tebruegge M; ptbnet COVID-19 Study Group (2020) COVID-19 in children and adolescents in Europe: A multinational, multicentre cohort study. Lancet Child Adolesc Health 4:653-661

31. Mantovani A, Rinaldi E, Zusi C, Beatrice G, Saccomani MD, Dalbeni A (2021) Coronavirus disease 2019 (COVID-19) in children and/or adolescents: A meta-analysis. Pediatr Res 89:733-737

32. Eastin C, Eastin T (2020) Epidemiological characteristics of 2143 pediatric patients with 2019 coronavirus disease in China: Dong Y, Mo X, Hu Y, et al Pediatrics. 2020. J Emerg Med 58:712-713

33. Cucinotta D, Vanelli M (2020) WHO declares COVID-19 a pandemic. Acta Biomed 91:157-160

34. Guilpain P, Le Bihan C, Foulongne V, Taourel P, Pansu N, Maria ATJ, Jung B, Larcher R, Klouche K, Le Moing V (2021) Rituximab for granulomatosis with polyangiitis in the pandemic of COVID-19: lessons from a case with severe pneumonia. Ann Rheum Dis 80:e10

35. Angeletti A, Drovandi S, Sanguineri F, Santaniello M, Ferrando G, Forno R, Cipresso G, Caridi G, Riella LV, Cravedi P, Ghiggeri GM (2020) COVID-19 in children with nephrotic syndrome on anti-CD20 chronic immunosuppression. Clin J Am Soc Nephrol 15:1494-1495

36. Minotti C, Tirelli F, Barbieri E, Giaquinto C, Donà D (2020) How is immunosuppressive status affecting children and adults in SARSCoV-2 infection? A systematic review. J Infect 81:e61-e66

37. Santos CS, Morales CM, Álvarez ED, Castro CÁ, Robles AL, Sandoval TP (2020) Determinants of COVID-19 disease severity in patients with underlying rheumatic disease. Clin Rheumatol 39:2789-2796

38. Baker D, Roberts CAK, Pryce G, Kang AS, Marta M, Reyes S, Schmierer K, Giovannoni G, Amor S (2020) COVID-19 vaccinereadiness for anti-CD20-depleting therapy in autoimmune diseases. Clin Exp Immunol 202:149-161

39. Sharmeen S, Elghawy A, Zarlasht F, Yao Q (2020) COVID-19 in rheumatic disease patients on immunosuppressive agents. Semin Arthritis Rheum 50:680-686

40. Beyzaee AM, Rahmatpour Rokni G, Patil A, Goldust M (2021) Rituximab as the treatment of pemphigus vulgaris in the COVID19 pandemic era: A narrative review. Dermatol Ther 34:e14405

41. Aziz H, Lashkari N, Yoon YC, Kim J, Sher LS, Genyk Y, Kwon YK (2020) Effects of coronavirus disease 2019 on solid organ transplantation. Transplant Proc 52:2642-2653

42. Raja MA, Mendoza MA, Villavicencio A, Anjan S, Reynolds JM, Kittipibul V, Fernandez A, Guerra G, Camargo JF, Simkins J, Morris MI, Abbo LA, Natori Y (2020) COVID-19 in solid organ transplant recipients: A systematic review and meta-analysis of current literature. Transplant Rev (Orlando) 35:100588

43. Silvano J, Ferreira F, Bustorff M, Nunes AT, Tavares I, Sobrinho Simões J, Ramos A, Cardoso MJ, Sampaio S, Pestana M (2020) Viral clearance and serological response to SARS-CoV-2 in kidney transplant recipients. Transplant Proc 53:1180-1186

44. Menon S (2019) Acute kidney injury in nephrotic syndrome. Front Pediatr 6:428

Publisher's note Springer Nature remains neutral with regard to jurisdictional claims in published maps and institutional affiliations. 